\title{
Integrating the Spiritual-Cultural, Rights-Responsibilities, and Economics of a Citizenship Development Higher Learning through a Differently Conceived and Practiced Sociology in (Second Language) English in the Japanese University
}

\author{
Alan Brady \\ Department of Sociology, Kwansei Gakuin University, Nishinomiya City, Japan \\ Email: aybrady@gol.com
}

Received October 30 $0^{\text {th }}$, 2013; revised November 30 ${ }^{\text {th }}, 2013$; accepted December $7^{\text {th }}, 2013$

\begin{abstract}
Copyright (c) 2013 Alan Brady. This is an open access article distributed under the Creative Commons Attribution License, which permits unrestricted use, distribution, and reproduction in any medium, provided the original work is properly cited. In accordance of the Creative Commons Attribution License all Copyrights (C 2013 are reserved for SCIRP and the owner of the intellectual property Alan Brady. All Copyright @ 2013 are guarded by law and by SCIRP as a guardian.
\end{abstract}

\begin{abstract}
School classroom life and study can be thought of as a threefold social sphere which encompasses the economic, the rights-responsibilities, and the spiritual-cultural. In order that there be a healthy threefold social sphere in the classroom, all three intertwined sub-spheres must be equally developed and work together. Human development and the instilling of socially beneficial values in young people are the publicly stated goals of Japanese education at all levels in Japan. Language of wider use and communication (LWUC) English medium study integrated with and directed by content study in a one-world ontology of knowing and communicating, has an important role to play in the implementation of this goal. However, to do so requires the creation and nurturing of an intersubjective well-being class study framework that can serve as an ongoing resource to create opportunities for civic dispositions to be learned and relearned. A study framework is required that prioritizes 1) people over technology; 2) progress over status quo arrangements; 3) the valuing of study over operational or epistemic outcomes; and 4) a process co-constructed and evolving curriculum over a closed already decided and other-directed curriculum and syllabus. This study framework will contribute to enhancing individual and communal awareness of participants' civic responsibility.
\end{abstract}

Keywords: Social Threefolding; Citizenship Development; CLIL (Content and Language Integrated Learning)

\section{Introduction}

This writer is an English language and sociology of education researcher-practitioner at a university in western Japan, Kwansei Gakuin Univerrsity (KGU). English language study in the Sociology Department where I work is confined to first and second year general education, and is viewed in the Department as peripheral, and at best auxillairy, to study in the specialtyarea (native language Japanese) mainstream part of the curricular provision. English language is not institutionally accepted as a medium of sociological practice learning, but remains entrenched as a lower priority, separate and separated subject-object of study. Students are expected to connect English language communication with sociological study on their own without any institutional assistance. Nevertheless, "Sociology in English” is a buzzword in the Sociology Department, though it has more of a public relations' role and responsibility than teaching or researching recognition or acceptance. The Department prides itself on being a "global sociology" higher education entity. Having a small percentage of the department's curriculum provision and research in a language of wider use globally (English) would, therefore, have valid educational significance.
I thus decided in my class teaching to make explicit connections between language-communication and social life learning where students actually experience in their study a "sociology in English" to explore the ongoing living nature of social life as it unfolds in the classroom. School classroom life and study can be thought of as a threefold social sphere-following Steiner, cited in Lamb, (2008) - which encompasses the economic, the rights-responsibilities, and the spiritual-cultural. Put another way, social life in the classroom involves power relations and rights-responsibilities (political relations and considerations), caring and sharing and cooperatve-collaborative endeavors (spiritual-cultural relations and considerations), and competitive individual development (economic relations and considerations). In order that there be a healthy threefold social sphere in the classroom, all three intertwined sub-spheres must be equally developed and work together.

\section{The Importance of Inclusive Social Threefolding in Classroom Teaching and Learning}

What any society values and sees as ideal often gets taught in 
schools. Furthermore, what and how children are taught results in their developing certain ideals and values that are perpetuated in the wider society once these students become adults and go into society as local and global citizens. These values may very well include in this modern capitalistic-bent world of ours, a competitive ethos, a conviction that meritocracy is the norm, a view that instrumental-extrinsic motivations are more important, and an excess valuing of academics (i.e. knowledge and skills) over values/ideals and social or emotional development. Schools are also, Giroux (1992-93) maintains, terrains of struggle or places and spaces where contradictory values and ideals compete for prominence. Proponents of a democratizing education argue that people who are given freedom and choice will eventually become better democratic citizens simply because they have learned how to negotiate with others, to identify obstacles and paths of resistance, to know themselves and others. They are also open to change and listening to others as they all consider themselves to be vital to the development of a vibrant and healthy social threefolding.

Christainsen, Garvin, and Sweet (1991) contend that higher education has become more isolated from the kinds of learning people require for their life competencies. The main value that a higher education can impart to students, they argue, is a predisposition to love learning across the curriculum above any ability to learn only in any one or more isolated part(s) of that curriculum. This pre-disposition is far more urgent than that students passively bank knowledge, skills, values, or ideals, or that they (students) are not themselves actively engaged in constructing or reconstructing their learning. Abe, Perrin, and Woolbright (1995) go further in maintaining that a higher education's main role and responsibility is to help students define the important characteristics of adult citizenship.

There is, and has been for a very long time an urgencythough too few people have too infrequently recognized it or advocated for it - for a higher education mission integrating a language of wider use and communication (LWUC) English, and academic and social development content in the Japanese university context. Brady (1997) argues that,

The continued acceptance and practice of isolating communicative English language teaching and research from native language (Japanese) academic study bodes ill for the future and further development of the university in Japan (Brady, 1997: p. 85).

Engllsh as a LWUC can ahelp students, faculty and the university community as a whole increase their awareness of local and global society and their social roles as Prodromou (1992) argues.

what we teach and particularly the way we teach reflects our attitudes to society in general and the individuals' place(s) in society. It also reflects our eduational practice as an implicit statement of power relationships, of how we see authority in the classroom and outside. Just as the mother tongue in Freire's Pedagogy of the Oppressed becomes a process of increasing consciousness of one's society, so too may the teaching and learning of (and in a foreign language. (1992: pp. 74-75)

Success in language teaching and learning in Japan, including most unfortunately at the tertiary level as well, is too often conceptualized and practiced - and measured for its success as well-in terms of how well students bank their study-passively learn or acquire reading, writing, listening, and speaking knowledge and/or skills in their engagement with or use of the language. Students' language learning may be primarily meas- ured for its "success" in how well they "master" linguistic language (e.g. grammatical competence). and/or pass competency examinaions. If students are fortunate enough they will have teachers who prioritize intercultural communicative competence learning. But as necessary as this aim might be for language engagement and use, it is not in and of itself sufficient to help students link their language learning with social change and participation.

A life-long love of and for language study/learning and intercultural communication contributing to a participatory citizenry for constructive social change can only happen if teachers and the syllabus respond to students' needs to connect the language they study and learn to the real concerns that they have in their lives, which involve school, family and relationships, changing identity formation, curiosity and uncertainty, and worries about the future. This is a responsive view of language study supported by a great many applied linguists such as Littlejohn (2004), Lange (1994), Brady (1997), and Brady and Shinohara (2000).

According to Tanabe (1978) English in Japan operates as a borrowed subject/object language, not as a language of wider use or communication, or as a locally or globally useful means of intercutural communication. Imamura (1978) argues that university faculty engaged in the teaching and researching of English language must re-examine their basic approach to language education, and is concerned with the following five issues:

1) What is language and language study for?

2) Why teach and study/learn language?

3) Which non-native (i.e. non-Japanese) language(s) need be taught and studied in Japan?

4) Who benefits and how do they benefit from such study?

5) How should language be taught?

Suzuki (1978) pointed to a perhaps more fundamental problem with the conceptualiation and practice of English study at university. He noted that there is far too inadequate attention to and concern with language study as (my italics) educational growth. Mark (1990) has offered a multi-dimensional view of language teaching and learning — cited in Brady (2006) — which highlights the role of language teachers as educators where,

in the language learning process the teacher and students alike have room for personal growth and betterment in understanding themselves and the world we live in. (Mark. 1990:11)

Bisong (1995) believes, and I agree, that English as a language of wider use and communication opens up new opportunities for a society and its people. It can, he says, help a society become multilingual and multicultural, and also offer its citizens a richer linguistic repertoire and an expanding consciousness. Beyond the many limitations of English language study which have existed in Japan for far too long, LWUC English study, integrated with content as the driving force, has the potential to help university students develop a more flexible and critically aware approach to their study and learning.

It is the main argument of this paper then that an integrated and self-directed, student engaged teacher led and assisted social threefolding, which combines the study/learning of and in a language of a locally and globally useful wider use and communication (i.e. English LWUC) with academic and social development content (e.g. sociology study), can best satisfy the concerns of educators who hope to develop an active and well-educated adult citizenry to contribute to and nurture their local and global societies. As Barnett $(1997,2000)$ contends, a 
higher education must provide students experiences which encourage them to 1 ) reflect on their thoughts and actions, 2) reinterpret presenting situations where they see the curriculum not as an imposition but as a set of possibilities and practical hopes framed in large part by themselves, and 3) develop a continuous expression of both a skeptical and questioning outlook geared to the continuous and recursive reappraisal of their own individual and collective learning.

\section{What Is a Higher Education Global Citizenship Integrated Language and Content Development?}

Blanton (1992) argues, and I agree, that education often violates the deepest needs of the human spirit by 1) alienating and boring or dulling teachers and students/learners, and/or 2) by failing to address in any meaningful ways the real issues of importance in our lives. These real isues have been articulated by Splitter (1995) as follows:

a) Does (my) life have meaning, and if so, what is that meaning?

b) Do I have gifts that the world wants and needs?

c) Who and what can I trust?

d) How can I rise above my fears and prejudices?

e) How do/can I deal with suffering, my own and others?

f) How do I keep hope(ful)?

Splitter (1995) argues that educational quality must be defined in terms of the thinking and feeling development of students. Schools, in his estimation, are and continue to be agents of manipulation as well as preservers and protectors of the status quo rather than facilitators for personal and social enrichment and liberation. Most schools, says Splitter, confuse educating with a far more narrow and primarily economicoriented view of training, an idea that is supported by people such as McVeigh (2002), and Refsing (1992) in particular. Teachers concerned with developing a deeper more critical thinking and feeling in students must recognize, he says, that "in the real world outside the classroom thinking among ordinary citizens may be more of a threat than a priority” (1995:1).

There are certain dispositions, according to Splitter (1995) which can guide a philosophy of thinking and feeling for those educators who wish to go beyond training students whether for jobs or to fit into society as it is already constituted, which Forbes (2005) calls responsibility to society These dispositions are:

a) argumentation skills,

b) inquistive skills, especially the seach for reasons and not accepting what is given and true,

c) identification, modification, and application of criteria to form judgments and make decisions,

d) making distinctions to allow people to see the complexity of a situation, event, problem or solution, an act or decision,

e. the ability to identify relationships to help us make sense of things (i.e. causes and effects, means and ends, parts and wholes),

f) the exercise of moral imagination by which we think of different ways about doing things

Splitter's advocacy of what he calls a "philosophy for thought" needs, however, to be expanded and widened to include spiritual higher learning, especially when that study and learning takes place at/in a Christian or any other faith-created institution such as is the case at Kwansei Gakuin University in the Kansai area of Japan, where this writer teaches and re- searches in that university's Sociology Department. How can we teachers find ways in our study with students to explore those deeper dimensions of teaching, learning, and living? By spiritual is meant the never-ending human quest for connected-ness with others and the world we see and experience, as well with all that which we can not possibly know or see for certain, something larger and more trustworthy than our own egos, in short, the total mystery of our being alive together and sharing life together.

When we higher education teachers and students enter the classroom we bring our physicality and spirituality with us, so we can choose to either reflect upon or avoid those questions we live with every day, and how we are living them. We teachers, can if we choose, together with students, prioritize dialogue over lecture, collaboration and cooperation over competition, and democracy over authoritative control But interrogating the truths that we together live in class, and which can be extended to our lives outside class as well, can easily conjure up fears that somehow we all need to "fix" one another and solve "problems." How can we get over this reluctance to spirituallyculturally, economically, and politically engage with one another?

One way might be for us as teachers to consensually, caringly, and cooperatively - but never threateningly or imposingly -adopt with students an agreed-on study framework with ground rules that once adopted can release us from our fears and anxieties, and at the same time teach us all to live our questions with one another rather than forcing ourselves to have to find "correct" answers to them. This we can do by dialogically opening up to one another-we to students, and students to us and each other-using life content topics to spur us to ask questions, to guess and predict (if possible) what may or may not be, to make tentative conclusions - not protestations or pontifications - about why things are or might be as they are.

Greene (1993c) believes that to truly have a shared learning experience teachers must make special efforts to listen more to students' voices in order for teachers to discover and act about what they, our students, are thinking and feeling, what most concerns them, what has meaning in life both inside and outside the classroom for them. This prime attention to students' voices, however, can create tensions with systems especially, where the overall agenda of study and learning revolves around system and teacher control, and which focuses primarily if not exclusively on our individual and socially collective responsibilities to society, not for any re-making of society.

Prime attention to students' voices can create empowerment possibilities where, as Banks (1991) points out, knowledge and skills are not neutral. Both knowledge and skills, however we define them, are important purposes or instruments if you like to help people improve the quality and spirituality of their immediate classroom society and hopefully by extension, society in the wider more global world. Education must light paths for social change. This obligates us as teachers and educators to lead young people to promote constructive change(s) towards more just and compassionate and sustainable approaches to living and learning in a rapidly changing and increasingly complex, puzzling, more globalized, and at the same time more fragmented world.

I believe that this attention to, and concern for, developing in young adults their local and global citizenship development in class study must involve the following:

a) democracy in real-time and an end to systemic control and 
unquestioned teacher authority in study and learning,

b) prioritizing what Bollinger et al. (2003) call a one-world ontology of knowledge and communication,

c) responsibility in class to (our) society and for (our) society,

d) prioritizing the "phronesis" or process value of study over its operational (skills) or epistemic (knowledge acquisition) results or product,

e) a commitment to Splitter's philosophy for thought,

f) a post-method approach to higher language learning and educating,

g) a strong or stronger communicative language teaching (CLT) than now prominently reigns in language pedagogy,

h) re-conceptualizing and differently practicing an integrated language (sociology) content higher learning

The question then arises of how we can conceive and practice a content-driven language and interactive communicatively engaged learning? Murphy (1996) believes that a theme-based integrated content and language approach allows students to become knowledgeable, curious, and inquisitive about things of importance, concern, and interest. As this knowledge base grows, Blanton (1992) argues, vocabulary and other linguistic forms also grow at the same time simply because knowledge of whatever sort has no way of existing or means of expression without language and interactive communication. Lange (1994), commenting on the concept and practice of curriculum delivery, maintains that the curriculum (i.e. the learning plan), and practice or instruction (i.e. the coupling of that plan to students as they learn), are influenced by and influences students' conceptualization(s) of the world and their place in the world. The focus of any language instruction and learning, in his estimation, is to develop competence and confidence to comprehend and use language. Such a focus connects the study of and in language to the content of almost any discipline, as well as the student-learners' personal, social, and political contexts.

Higher educators, particularly those involved in language education which prioritizes communication and active interaction, need to constantly wonder why language study and learning is important and what the language requirement is for. Analysis of language and/or any approach which treats language as isolated compartmental subject or object learning, whether "communicatively-oriented" or not, is not sufficient to justify the inclusion of a language learning component in a specialized content-area higher education such as sociology. The proper orientation, says Lange (1994):

must be toward a level of language use or proficiency where students use that proficiency to learn about themselves in the world ... it is at this point that language learning becomes an important element in a higher education. The suggested principle only works with cooperation in other areas of the liberal or specialized curriculum to provide for language use (1994: 4)

Hallet (1999: p. 24) argues that expanding students' communicative competence when studying (in) a content area and teaching through a language other than the native language equips students with the necessary skills to communicate more confidently and easily about 1 ) their own culture and society/ civilization, 2) history and geography, 3) the socio-cultures of the target language, and 4) universal and global experiences and intercultural and multicultural phenomena. Additional aims and "payoffs" of an integrated content and LWUC university education can be a) to introduce students to the textual discourses of a particular discipline (e.g. sociology), b) to help students develop academic literacy skills in the LWUC, and c) to teach students discipline-specific vocabulary that can and will help them pursue their future careers and also prepare them to continue their studies in the LWUC at a postgraduate level.

Horio (1995) maintains that Japanese students are deprived of sufficient opportunities to think or feel on their own. They are also deprived of having any significant input or investment into the kind of learning necessary for them to be creative and individual and socially responsible thinkers and doers. They are not given enough opportunities to cooperate rather than compete in their learning. By the time students arrive at university, Horio says they are expected to have what can be called a "self-organized criticality" but may be seriously unprepared to meet this expectation. The key to preparing students for the uncertainties of life, and those decisions which must be made in light of uncertainties, lies with the ability and willingness of teachers to help young people find their own forms and avenues of participation, and their own ways and means of effecting constructive social change in their own lives and the lives of their fellow citizens.

Higher education, crucially including the language study provision, cannot contribute to citizenry or national development unless it abandons its operation as a passive activity with fixed curriculum, authoritative control structures, and other status quo arrangements that justify a continued banking knowledge transmission path to study and learning. I will now continue this story by using additional social science/sociological and applied linguistics research support to further conceptualize and give hope of actually practicing the above.

\section{Reconceptualizing the Practice of a Sociology in English: Social Science and Higher Language Educational Concerns}

Social science support for an integrated content-language learning (CLIL) centered on a socially responsible and accountable citizenship development comes from Bauman (1989: 179) who argues:

The existential modality of the social (unlike the societal) has been seldom held at the focus of sociological attention. There is no sociological consensus as to the meaning, experiential content and behavioural consequences of the primary condition of being with others'. The ways in which that condition can be made sociologically relevant are yet to be fully explored in sociological practice.

Barnes (2000) maintains that the relationship between the individual, society, and social structure has not been addressed with proper regard for social interaction. Society is often conceived in purely structural "otherness" terms, or in very individualistic terms. Too much attention is given to the subjective and the objective at the expense of the intersubjective. Barnes argues that the central problems of sociology are those of collective or social agency.

"Responsibility" has not been a compelling central element in the construction of any major social theory where,

understanding the everyday employment of this concept, with its double significance - psychologically it implies internal capacities, sociologically it implies liability and answerability - is also (my italics) the key to understanding of the role of 'choice', 'agency', and related concepts in everyday contexts. (2000: xii)

Johnson (1997) argues that in a modern society that values 
individualism and is dominated by it, the idea that a society is just people may seem obvious. This is true of classroom society as well. Yet, this approach ignores the difference between people who participate in social life (e.g. class study), and the many varied relationships that connect participants to one another and to other groups and societies through their participation in a social life system such as schooling. People, says Johnson, often participate in systems without feeling or believing they are a part of them, and that they in fact make them happen. The "classroom" "social study" system is not simply comprised of an aggregate of individuals.

Class social life is a system with connected individuals and connected groups who participate and relate to each other in a number of ways. People are what make any system "happen," and without their participation any system exists only as an idea with some physical reality attached. Nevertheless, a system affects how we think, feel, and behave as participants. People make systems happen, and systems lay out paths of least resistance to shape participation. Johnson (1997) says that of what we accept as reality consists not of things as they really are, but of ideas that we develop about things as we think, feel, or believe they are, where believing is seeing. The classroom is a real social context, and is, according to Andrewes (2005), more than the study of language or content "out there" in the "real world.” The classroom can be used for communication development and knowledge acquisition, where the main role of language, communication, and knowledge-building in social life is neither functional nor strategic, but affective. Classroom social life can be directed towards defining and molding relationships in a community. We always participate in something larger than ourselves (i.e. systems). As social life flows from this relationship, we need to consider that we are all involved, if only indirectly, in any social consequences that result, whether beneficial or not.

Simply making a connection between sociology content and language learning by itself, however, is not sufficient for students to better understand the nature of responsible and accountable social life. I believe sociology students can better understand "sociology in English" if they are actually involved in experiencing the nature of their own unfolding social life in their learning, rather than looking at social life as an "outside self” subject or object. Sociology in English" should be conceived, and practiced, as a one-world ontology exploration of 1) our knowing about the social world, and 2) what we communicate and how we communicate with each other about social systems and our participation in them. A "sociology in English" is 1) social life in shared and connected participatory communication, and 2) shared and connected participatory communication in social life.

How life transpires inside class has potential to transform the quality of life that goes on outside class when study is focused on the life-world of the community as a whole, not on individualistic "what's in it for me" concerns. Content and language integrated learning or CLIL is an approach which has gained currency among language educators who seek to connect language learning with content-knowledge acquisition and engagement. The teaching approach, outlined in part $\mathrm{V}$ of this paper, is also a response to what Johnson (1997), Sandelands (2003), Baumann (1989), King (2007), Forbes (2005), and Barnes (2000) feel is most urgent in sociological practice: re-directing it away from the study of social life as the life of interacting individuals, towards a more socially responsible study of the lived nature of cooperative social life itself.

Andrewes (2005) maintains that classroom social life, which focuses on language-communication development, and/or knowledge acquisition, does not usually exploit opportunities for participants to develop personal and social relationships to support and promote the social life learning process. CLIL focusing on responsibility to and for society, can help cement interpersonal relationships within and between connected groups of people. CLIL also builds intercultural knowledge, develops intercultural skills, and provides opportunities to study social life content through different perspectives. Research also shows that CLIL study frameworks diversify methods and forms of teaching practice, and enhance participants' awareness of different ways of 1) understanding the world, 2) what and how we communicate about the world, and 3) our place in the world as connected individuals participating in social systems.

Littlejohn (2004) believes that it is an illusion to think class language study practices have little impact beyond the learning of language. As educators, language teachers are uniquely positioned in helping to shape the views that young people have of themselves in relation to learning in general, and their relationship to and participation in systems of oppressive authoritarianism and control. Language educators can shape how young people see and value themselves as active or passive agents. Language educators need to help students develop a questioning and skeptical attitude, and what they do depends on their own sets of values and priorities, and as Littlejohn argues, their political stance as well. As much as our practices in class emulate or should emulate individual and social responsibilities to society, we have an obligation, says Forbes (2005), to make a coherent and principled contribution to shape the future by being responsible for society.

\section{A Critical Prerequisite for an Experiential Sociology in English CLIL: The Necessity of a One-World Ontology of Knowing and Communicating}

Bollinger, Nainby, and Warren (2003) perceive a conceptual divide between contemporary communication theory and critical educational practice. At present there exist, they argue, conceptually two separate worlds, one the world we communicate with or the entire set of symbols, sounds, gestures, pictures and other things we use to communicate. The second world is the world we talk about, all of the various subjects that move us to talk to one another. Bollinger, Nainby, and Warren believe teachers must work with students to rethink and interrogate how and why we constitute the world as we do. In a one-world ontology the two stages become one where knowledge and reality can be unmasked and recreated simultaneously.

Representational two-worlds ontology models, they maintain, fail to account for the complexity of lived experiences of people in class, where the emphasis remains on systemic meanings rather than minute immediate communicative acts. Building on Freire (1970) and Stewart (1995), Bollinger et al. assert that human conditions are fully constituted in and through social interaction, and can be changed by social interaction as well. Two-world assumptions can affect exploration with students of the socially-constituted nature of, for example, exploitation and any pedagogical possibilities to create the goal of transforming exploitative conditions. Communication, they maintain, forms 
the essence of social life, unifying humans and the world in which people live; communication is not a mere tool-instrumental means to achieving human world-shaping.

A one-world ontology, where language and communication have immediate effects on teaching and learning practice(s), can redirect CLIL toward a more exploratory, experiential, non-technical , and non-epistemical, life valuing phronetic approach advocated by Flyvbjerk (2001). But more than an ontological vocabulary is necessary. Young adults in Japan come from pre-university schooling that has, for the most part, been decided for them and where they have had little if any investment in decisions taken on their curriculum. It is necessary to set up teaching and learning structures in class where students have rights and obligations to voice, to question, to actively participate in shared understandings, and to make educated guesses about things they do not know.

What sort of pedagogy can be generated in the process of class interaction? What kind of thinking, feeling, and behavior changes can be fostered by that engagement? Can students in a one-world ontology of study and learning have opportunities to better understand the relationships between (their) communication and the material conditions of their (individual and social) lives, and how their lives are ongoing and sustained by the many choices they make every moment in class and whether they choose paths of least resistance or not? Can students also have opportunities to see the social hegemony that is instituted in education and social life? Furthermore, can they learn to experience in their here-and-now shared participation in communication the constraints the world has over them and the transformative possibilities they have over the world (Shor, 1996)? In the concluding two sections I will answer in the affirmative to all three questions.

\section{Practicing a CLIL-Citizenship Development Social Life Learning}

What "happens" in class social study life can change the way(s) in which a system functions and how people choose to participate in that system. Likewise, the way(s) in which that participation happens, and how teachers treat students in class, can dampen or increase students' sense of individual and social agency as they participate in a system.

Teaching language has epistemical-knowledge-building and technical linguistic aim(s), and also more general educational objectives such as socialization, cognitive development, and emotional development. Understanding roles, rules, cultural behavior, and structured participation in social life in the classroom can help develop students as explorers of their ongoing participation in social life, and consequently develop their awareness and embrace of interdependence over independence and dependence.

To effectively integrate language, content, and social and civic responsibility learning we must create the atmosphere, procedures, norms, expectations, and demands in classrooms that we see and would like to see outside in the wider more macro systems of social life. Our teaching-learning environment should reflect the values to which we hope the wider more macro society aspires, and we must make a conscious effort to create that valued improvement in our immediate class society. Students should be provided with venues for cooperative as opposed to competitive learning which can heighten their shared participation in schooling as they experience that system in class.

Flyvbjerg (2001) has argued that instead of trying to emulate the natural sciences, the social sciences should be practiced as phronesis. Phronetic social science focuses on four value-rational questions: 1) Where are we going? 2) Who gains and who loses and by which mechanisms of power? 3) Is this development desirable? 4) What should we do about it? The CLIL-citizenship development study framework in my class instruction is based on phronesis as much as it is concerned with experiencing, in shared participation in social life, a sociological imagination. A CLIL-citizenship development is not an end goal in and of itself, but serves to teach class study participants the value of a cooperative and collaborative learning that engages with knowledge and communication of social life.

Building and nurturing sociologically imaginative civil society in the classroom begins with students and I together proposing and agreeing to discuss topics that affect our lives on a daily basis in class and outside class, and which can help us work towards a greater awareness and understanding of the connections embodied in Flyvbjerk's four value rational questions. A number of class study topics are suggested at the beginning of term, and I ask students' permission to allow me to raise one topic in particular to jump-start our topical dialogue. The first topic we engage in is whether or not we will value study together individually and/or collectively/communally. With students' consent, either by a vote of hands or secret ballot, we start our study with discussion on the merits of cooperative and/or competitive study, and what group study will be like, if we chose to form smaller groups. How many members will each group have, what needs to be done and who will do what needs to be done, for example?

This first topical discussion is held in English in public whole class talk that I lead, but after groups are formed, is conducted in groups in either English or Japanese as class members decide. After/if we have decided to conduct study collectively and cooperatively-I also take time to advocate the benefits of cooperative learning over competitive learning-we then work our way through other study issues that will help determine where we are and are going, who wins and who loses in where we are going, and what behavior we expect of ourselves in where we seem to be headed in our study.

Among the topics suggested by me or by students are:

1) What communication language(s) can we or should we continue to use and why?

2) What area(s) of social life, besides that in this classroom, would we like to study together as a large group.

3) Do we need to prepare for our study every week, and if so, how? Do we need to review previous study and if so, how?

4) How shall we evaluate teaching and learning? If we have "tests, why and who makes them? How are they made and taken? What will "test" results be used for? What kind(s) of other evaluation(s) may be necessary and why?

5) In our study of social life, is, for example, history, geography, economics, and anthropology necessary? Why or why not?

6) Who makes decisions, how will they be made, and about what week-to-week?

7) Do we need to have social life study rules, and if so what rules, and who makes them and how? Do we agree to keep to the rules we consensually make or not? If rules are "broken" what do we do? Are there "penalties"?

8) What are some "things" we (ought to) value in our study 
together? For example, do we value raising questions or not, and if so about what? Do we value listening attentively to another/others when they speak?

The purpose of these start-of-term activities is for us to bond together as connected individuals and groups in our study, and to get some ideas about what aspects of social life in particular we wish to investigate more fully as the term goes on. In that regard, I advocate the benefits of studying one or two areas of social life for the rest of the term rather than jumping from one to another system area topic week-to-week. But this advocacy is not imposed on students. Everything that we discuss or do is reviewed and reflected upon in the shape of reflection notes, prepared first by myself as an imperfect model of what one can recall of a decision discussion, or activity. After the first, second, or third class meeting reflection notes are voluntarily prepared by students as group notes-if students have chosen to form groups-and/or by individual students where we compare our recall and understanding(s) of what we have done in our previous social life study. The class is further structured with time allotted to 1) whole-class and group greetings, announcements, and shared small talk, 2) submission of and review of previously agreed upon homework-with sufficient copies to myself and other groups of students, 3) negotiated discussion of new study and/or study already begun, and 4) further study and learning opportunities which recognize our responsibilitites both to and for our study-learning society.

This last structural arrangement I have labelled the difference between a "set menu" and an "a la carte menu" of study. The former is what we are obligated to study according to the already set departmental and/or course/class misson and guidelines, whereas the latter is what we together can choose to study or do free from contraints placed upon us by, for example, a uniform text, a uniform test or tests, or the institutionally otherdirected set goals of our study. This conceptual and practiced CLIL framework aims for students not only to participate in the planning and practice of the curriculum, but to take control of their study and learning, McKinney (2007) observes that it is necessary for study participants to be much more attentive not only to what they study (knowledge), or the skills they utilize to enhance knowledge learning. They need, McKinney argues, to hone in on how they study and how they value what and how they study through shared dialogue. Though my attention remains fixed on students as individuals and as members of freely chosen groups, the learning focus, however, is on shared communal learning, and in particular, how we can use the intersection of our shared language and communication and social life knowledge-building to drive and nurture a healthy threefold civil and civic-moral society in class from one week to the next.

\section{Concluding Thoughts}

One definition of global citizenship states that if young people need to be empowered as citizens then they need to learn in an environment that actually recognizes them as citizens, and which treats and respects them as citizens. In such an environment, it is critical that participants are provided numerous opportunities to practice and develop dispositions which enhance their citizenship responsibilities (Time for Rights, Unicef and Save the Children, 2002). The many decisions taken in class study, choices that are or are not made about, for example, what and how to study, or whether smaller groups and study rules need be formed and how, can and ought to be better understood by connected system participants.

Students need to be more fully aware of who they are, not only as individuals or groups, but more importantly as socially connected individuals and groups. They need to be aware of how the world and its social life systems affect them, and also how they can have control over how the world affects them through their active participation in systems. Systems do not change unless relationships change, especially where and when people choose or do not choose to take paths of least resistance. Schooling is as much about what people do as it is about associations we may have with the idea of schooling as a social system. What happens in the system (i.e. schooling and the classroom) depends to a large extent on the situation the participants are in, and also how they choose to participate.

Class study culture consists of symbols, especially words, contained in a language or languages, and various kinds of ideas about everything from our relations with one another to the meaning of our and others' lives. Schooling as a social life system is an ongoing process being a work always in progress. Integrated CLIL-citizenship learning can help students see schooling as micro interaction of connected individuals and connected groups and as macro social systems in which they are part. As schooling unfolds, it emerges from how we choose from moment to moment what we are going to make of it. One-world language-communication-knowledge development, and on-going classroom social life are not subsidiary to knowledge about the world outside the classroom. Students' understandings of social life and society are not distinct from how they experience their own immediate "society" as it unfolds.

If we as university language educators choose to focus on helping our students develop a heightened sense of local and global citizenship in a world that is being continuously connected and fragmented at the same time, and also help instill in them moral and civic responsibilities to self and to others, we are obligated to treat them as full citizens with 1) rights and responsibilities, 2) altruistic economic aims, and 3) spiritual and cultural empathy and inclusiveness. Human development and instilling socially beneficial values in young people are the publicly stated goals of Japanese education. LWUC English medium study integrated with and directed by content study has an important role to play in the implementation of this goal. However, to do so requires the creation and development of an intersubjective well-being framework for study that can serve as an ongoing resource to create opportunities for civic dispositions to be (re)learned and practiced regularly. The key to creating and nurturing this framework is a cooperative, collaborative, and collective thought and action by and of teachers and students to inquire into, for example, sources of knowledge and differences in values and ideals. A study framework that prioritizes people over technology or rules or status quo arrangements will contribute to enhancing communal awareness of civic responsibility, both on a local and more global scale.

\section{REFERENCES}

Abe, H., Perrin, K., \& Woolbright, D. (1995) The evolving of a curriculum. ON JALT'95, Proceedings of the 1995 JALT (Japan Association of LanguageTeachers) Conference, 26-29.

Andrewes, S. (2005). Towards a post-communicative approach? Life beyond CLT. Modern English Teacher, 7, 4-9.

Banks, J. (1991). A curriculum for empowerment, action, and change. In C. Sleeter (Ed.), Empowerment through multicultiral education 
(pp. 125-142). Albany, NY: SUNY Press.

Bauman, Z. (1989). Modernity and the holocaust. Oxford: Polity Press

Barnes, B. (2000). Understanding agency: Social theory and responsible action. London: Sage Publication.

Barnett, R. (1997). Higher education: A critical business. Buckingham: SRHE and Open University Press.

Barnett, R. (2000). Realizing the university in an age of supercomplexity. Buckingham: SRHE and Open University Press.

Bisong, J. (1995). Language choice and cultural imperialism: A Nigerian Perspective. ELT Journal, 49, 122-132.

http://dx.doi.org/10.1093/elt/49.2.122

Blanton, L. (1992) A holistic approach to college ESL: Integrating language and content. ELT Journal, 46, 185-193. http://dx.doi.org/10.1093/elt/46.3.285

Bollinger, C., Nainby, K., \& Warren, J. (2003). Articulating contact in the classroom: Towards a constitutive focus in critical pedagogy. Language and Intercultural Communication, 3, 198-212. http://dx.doi.org/10.1080/14708470308668105

Brady, A. (1997). English as an additional language (EAL): Language policy and planning at university for non-language majors. Kwansei Gakuin Sociology Department Studies, 77, 85-122.

Brady, A., \& Shinohara, Y. (2000). Principles and activities for a transcultural approach to additional language learning. System, 28, 305322. http://dx.doi.org/10.1016/S0346-251X(00)00014-2

Christiansen, C. R., Garvin, D. A., \& Sweet, A. (1991). Education for judgment: The artistry of discussion leadership. Boston: Harvard Business School Press.

Flyvbjerg, B. (2001). Making social science matter: Why social inquiry fails and how it can succeed again. Cambridge: Cambridge University Press. http://dx.doi.org/10.1017/CBO9780511810503

Forbes, S. H. (2005). On socially responsible education. http://www.putnampit.com/educate.html

Freire, P. (1970). Pedagogy of the oppressed. London: Penguin Books.

Giroux, H. (1992-93). Border crossings: Cultural WOrkers and the politics of education. New York: Routledge Press.

Greene, M. (1993c). The passions of lpuralism, muticulturalism and community. Educational Researcher, 22, 13-18.

Hallet, W. (1999). Ein didaktisches modell fur den bilingualen Sachfachunterricht. The bilingual triangle. Neusprachliche Mitteilungen, I, 52, $23-27$.

Horio, T. (1995) Educational thought and ideology in Japan: State authority and intellectual freedom. Tokyo: University of Tokyo Press.

Imamura, S. (1978). Criticism on TEFL (Teaching English as a foreign language) in Japan. In Koike et al. (Eds.), The teaching of English in
Japan (pp. 15-22). Tokyo: Eichosha Press.

Johnson, A. G. (1997). The forest and the trees: Sociology as life, practice, promise. Philadelphia: Temple University Press.

King, A. (2007). The sociology of sociology. Philosophy of the Social Sciences, 37, 501-522. http://dx.doi.org/10.1177/0048393107307665

Lamb, G. (2008). The threefold nature of social life. Biodynamics, 39-44.

Lange, D. (1994). The curricular crisis in foreign language learning. ADFL Bulletin, 25, 12-16. http://dx.doi.org/10.1632/adfl.25.2.12

Littlejohn, A. (2004). Language teaching for the future. http://www3telus.net/linguisticissues/language teaching.html

Mark, K. (1990). A language teaching model for the $21^{\text {st }}$ century. The Language Teacher, 14, 11-16.

McKinney, K. (2007). The student voice: Sociology majors tell us about learning sociology. Teaching Sociology, 35, 112-124. http://dx.doi.org/10.1177/0092055X0703500201

McVeigh, B. (2002). Japanese higher education as myth. Armonk, NY: M.E. Sharpe Press.

Murphy, J. M. (1996). Integrating listening and reading instruction in EAP (English for Academic Purposes) Programs. English for Specific Purposes (ESP), 15, 105-120.

http://dx.doi.org/10.1016/0889-4906(96)00019-1

Prodroumou, L. (1992). English as cultural action. ELT Journal, 42, 7383. http://dx.doi.org/10.1093/elt/42.2.73

Refsing, K. (1992). Japanese educational expansion: Quality or equality? In R. Goodman, \& K. Refsing (Eds.), Ideology and practice in modern Japan (pp. 116-129). New York: Routledge Press.

Sandelands, L. (2003). Thinking about social life. Lanham, MD: University Press of America, Inc.

Shor, I. (1996). When students have power: Negotiating authority in a critical pedagogy. Chicago: Chicago University Press.

Splitter, L. (1995). On the theme of "teaching for higher order skills". http://www.Shss.Montclair.edu/inquiry/ Summ95/splitter.html

Stewart, J. (1995). Language as articulate contact: Toward a postsemiotic philosophy of communication. Albany: SUNY Press.

Suzuki, Y. (1978). The importance of educational philosophy. In Koike et al. (Eds.), The teaching of English in Japan (pp. 71-90). Tokyo: Eichosha Press.

Tanabe, Y. (1978). Engish as an international language: Qualification, adaptation, and perspective. In Koike et al. (Eds.), The teaching of English in Japan (pp. 47-57). Tokyo: Eichosha.

Time for Rights, Unicef and Save the Children (2002). Learning about child rights and responsibilities.

http://www.unicef.org.nz/store/doc/1_RightsActivities.pdf 